\title{
Additive value of 3D-echo in prediction of immediate outcome after percutaneous balloon mitral valvuloplasty
}

\author{
Hazem M. A. Farrag ${ }^{1 *} \mathbb{D}$, Amr M. Setouhi ${ }^{1}$, Mustafa O. El-Mokadem², Mustafa A. El-Swasany ${ }^{3}$, Khalid S. Mahmoud $^{1}$, \\ Hesham B. Mahmoud ${ }^{2}$ and Alaa M. Ibrahim
}

\begin{abstract}
Background: Results of percutaneous balloon mitral valvuloplasty (BMV) are basically dependent on suitable patient selection. Currently used two-dimensional (2D) echocardiography (2DE) scores have many limitations. Threedimensional (3D) echocardiography (3DE)-based scores were developed for better patient selection and outcome prediction. We aimed to compare between 3D-Anwar and 2D-Wilkins scores in mitral assessment for BMV, and investigate the additive value of 3DE in prediction of immediate post-procedural outcome. Fifty patients with rheumatic mitral stenosis and candidates for BMV were included. Patients were subjected to 2D- and real-time 3D-transthoracic echocardiography (TTE) before and immediately after BMV for assessing MV area (MVA), 2D-Wilkins and 3D-Anwar score, commissural splitting, and mitral regurgitation (MR). Transesophageal echocardiography (TEE) was also undertaken immediately before and intra-procedural. Percutaneous BMV was performed by either multi-track or Inoue balloon technique.

Results: The 2DE underestimated post-procedural MVA than 3DE $(p=0.008)$. Patients with post-procedural suboptimal MVA or significant MR had higher 3D-Anwar score compared to 2D-Wilkins score $(p=0.008$ and $p=0.03$ respectively). The 3D-Anwar score showed a negative correlation with post-procedural MVA $(r=-0.48$, $p=0.001)$. Receiver operating characteristic (ROC) curve analysis for both scores revealed superior prediction of suboptimal results by 3D-Anwar score $(p<0.0001)$. The 3DE showed better post-procedural posterior-commissural splitting than 2DE $(p=0.004)$. Results of both multi-track and Inoue balloon were comparable except for favorable posterior-commissural splitting by multi-track balloon $(p=0.04)$.
\end{abstract}

Conclusion: The 3DE gave valuable additive data before BMV that may predict immediate post-procedural outcome and suboptimal results.

Keywords: Mitral stenosis, Percutaneous balloon mitral valvuloplasty, Three-dimensional echocardiography, Mitral valve score, Multi-track balloon, Inoue balloon

\section{Background}

Mitral stenosis (MS) is a common valvular affection by the rheumatic process, for which percutaneous balloon mitral valvuloplasty (BMV) was firstly introduced by Inoue for treatment of selected patients, as a safe invasive procedure with equivalent or even better results as surgical commissurotomy $[1,2]$. Nevertheless, safety

\footnotetext{
* Correspondence: dr-hazemfarrag@hotmail.com

'Cardiology Department, Faculty of Medicine, Minia University, Minya 61111, Egypt

Full list of author information is available at the end of the article
}

and success of BMV techniques are mainly dependent on the selection of suitable patients. Patient ages, functional class, mitral valve (MV) morphology, pre-procedural MV area (MVA), and the size of the balloon used; all are considered as predictors of procedural outcome $[3,4]$. Current scores that target patient selection before BMV-particularly the two-dimensional (2D) Wilkins score-may have many limitations including inability to assess commissural involvement or differentiate nodular fibrosis from calcification, ignoring the distribution of pathologic abnormalities and contribution 
of each variable and underestimating subvalvular disease [5]. Therefore, a new three-dimensional (3D) echocardiography (3DE) scoring system has been proposed by Anwar et al. for better guiding of MV intervention [6]. In the current study, we compared 3D-Anwar and 2DWilkins scores in assessment of MV before percutaneous $\mathrm{BMV}$, and investigated the additive value of real-time $3 \mathrm{DE}$ in the prediction of immediate outcome of the procedure.

\section{Methods}

The current study included 50 patients with rheumatic MS scheduled for percutaneous BMV, at the period from January 2017 to July 2018 Additional file 1.

\section{Inclusion criteria}

Inclusion criteria are as follows: (1) significant MS [MVA < $1.5 \mathrm{~cm}^{2}$ ], (2) favorable MV score [Wilkins score $<11 / 16]$, and (3) isolated MS or associated with no more than mild mitral regurgitation (MR) or other valve lesions not requiring surgical correction.

\section{Exclusion criteria}

The following criteria were basically excluded (1) MVA $>1.5 \mathrm{~cm}^{2}$, (2) associated moderate or severe MR or other valve lesions requiring surgical correction, (3) presence of left atrial (LA) and/or LA appendage thrombus, (4) history of recent thromboembolic events within the last month, (5) associated significant coronary artery disease requiring surgical revascularization, and (6) acute rheumatic activity and/or infective endocarditis [7]. The study protocol was approved by the institutional Ethical Committee and was in agreement with the "World Medical Association Declaration of Helsinki." After obtaining assigned consent from every participating patient, all patients were subjected to history taking and clinical examination, resting 12-leads electrocardiogram (ECG). Two-dimensional transthoracic echocardiography (2D-TTE) assessment was performed to all patients before and after BMV using IE 33 X-Matrix echo machines and X5-1 matrix array transducers (2007 Koninklijke Philips Electronics N.V.) with harmonic imaging and continuous ECG monitoring. Assessment of the MVA by pressure half-time (PHT) and planimetry, trans-mitral gradient, commissural splitting, MR regurgitant-jet area, and peak systolic pulmonary artery pressure (PSPAP) through tricuspid regurgitation peak velocity were undertaken. MV Wilkins score was estimated, that depended on assessment of four parameters (MV leaflets' mobility, thickness and calcification, and subvalvular involvement), and giving each parameter a score of 0-4. By calculating the sum of those scores, a total score of $0-16 / 16$ (normal $\mathrm{MV}=0 / 16$, mild $\mathrm{MV}$ involvement $=1-4 / 16$, moderate $\mathrm{MV}$ involvement $=5-$
$8 / 16$, and severe MV involvement $>8 / 16$ ) was obtained [8-12]. Two-dimensional transesophageal echocardiography (2D-TEE) using multiplane probe was performed to all patients immediately before BMV in order to assess the LA and its appendage for evident thrombi or spontaneous echo contrast, thickness of the inter-atrial septum, MV morphology and score (especially the subvalvular apparatus), and measuring MV annulus to determine balloon size. 2D-TEE was also undertaken intra-procedurally to confirm balloon position and assess incremental change in trans-mitral gradient and commissure mobility with balloon inflation, and look for any increase in MR [13]. Real-time 3D-TTE was undertaken for all patients within 24-48 h before and immediately after BMV using Philips IE $33 \mathrm{X}$-matrix echo machine and X5-1 matrix-array transducer (2007 Koninklijke Philips Electronics N.V.) with continuous ECG monitoring. Image acquisition was done according to Lang et al. [14] for assessment of MV and estimating the MVA [15]. Pre-procedural commissural affection and postprocedural splitting were assessed, where fusion of both commissures (anterolateral and posteromedial) indicated no splitting, width of splitting $<0.5 \mathrm{~cm}$ indicating partial splitting, and width of splitting $>0.5 \mathrm{~cm}$ indicating complete splitting. Each commissure was separately assessed and the total score was calculated ( 0 for no splitting, 0.5 for partial splitting, and 1 for complete splitting) [6]. MV score was estimated according to Anwar et al., where scoring was done for both MV leaflets and chordal affection. Each leaflet was divided into three scallops (anterolateral, middle, and posteromedial), and each scallop was scored separately for thickness $(0-1)$, mobility $(0-1)$, and calcification (0-2 except for the middle scallop where score was $0-1)$. Both anterior and posterior chordae were assessed at three levels: proximal (valve level), middle, and distal (papillary muscle level). At each level, chordae were scored for thickness (0-1) and chordal separation (0-2). The sum of such scoring of leaflets' mobility (0-6/6), thickness $(0-6 / 6)$, and calcification $(0-10 / 10)$, together with chordal thickness $(0-3 / 3)$ and separation $(0-6 / 6)$ can give the total score of $0-31 / 31$ (normal $M V=0 / 31$, mild MV involvement $=1-8 / 31$, moderate MV involvement $=9-13 / 31$, and severe $\mathrm{MV}$ involvement $\geq 14 / 31$ ) [6].

Percutaneous BMV procedure was undertaken using either Multi-track ${ }^{\mathrm{TM}}$ system (Numed Inc., Canada) or Inoue Balloon $^{\text {тм }}$ (Toray industries Inc., Japan) through trans-septal antegrade approach. Estimation of the balloon size for valvuloplasty was done by estimating the echocardiographic balloon reference sizing (3DE inter-commissural distance measured in mid-diastole), with the heightbased balloon reference sizing $(0.1 \times$ height in centimeter + 10) was used for those with inconvenient 
echocardiographic balloon reference sizing. The required balloon size could be equal, increase, or decrease by one or two sizes as the estimated reference size [9]. Optimal post-procedural success was defined by achieving MVA $\geq 1.5 \mathrm{~cm}^{2}$ and/or $50 \%$ increase than the preprocedural MVA, with less than moderate MR [7]. Obtaining suboptimal post-procedural MVA (i.e., < 1.5 $\mathrm{cm}^{2}$ ) and/or moderate or severe post-procedural MR were considered as suboptimal post-procedural outcome.

\section{Statistical analysis}

Statistical analysis was performed using the statistical package for the social sciences (SPSS) software [version 17 for Windows] (SPSS Inc., Chicago, Illinois, USA). Continuous variables were expressed as number and (\%) or mean \pm standard deviation (SD). Comparison between variables (pre-procedural and post-procedural two-dimensional echocardiography (2DE) and 3DE data, also between post-procedural 2DE and 3DE data) was done using Student's $t$ test, while comparison of postprocedural commissural splitting data (between 2DE and $3 \mathrm{DE}$, also between Inoue balloon group and multi-track balloon group) was done using chi-square tests. Z score was used for comparing between Wilkins and Anwar scores. Correlation of Wilkins and Anwar scores with achieved post-procedural MVA was done using Spearman rho correlation coefficient. Roc curve analysis was undertaken for Wilkins and Anwar scores in prediction of post-procedural suboptimal results. Statistical significance was defined as a probability level of $p<0.05$.

\section{Results}

The included 50 patients mean age was $29.5 \pm 7.8$ years (19-55 years old), and $64 \%$ of them were females. Thirty percent of patients had atrial fibrillation (AF), 66\% were in New York Heart Association (NYHA) functional class III, while $18 \%$ were in class II and $16 \%$ were in class IV. No significant difference regarding pre-procedural MVA as estimated by PHT, 2D-, and 3Dplanimetry $(p=0.244)$. Also, no statistical difference was observed regarding estimation of 2D-Wilkins score by TTE and immediate pre-procedural TEE $(p=0.176)$. Nevertheless, post-procedural MVA was underestimated by $2 \mathrm{D}$-planimetry than by $3 \mathrm{D}$-planimetry $(p=0.008)$. A significant increase was achieved in MVA after BMV $(p<$ $0.0001)$, with significant reduction in mean and peak trans-mitral gradients and PSPAP $(p<0.0001$ for all) (Table 1). Procedural success was obtained in $72 \%$ of cases, while $28 \%$ of cases had suboptimal post-procedural outcome (12\% had suboptimal post-procedural MVA, and $16 \%$ had significant post-procedural MR). Fourteen percent of cases had no change between the pre- and postprocedural degree of MR, 70\% developed new mild MR after BMV, while $14 \%$ and $2 \%$ had post-procedural moderate and severe MR respectively (Fig. 1).

Although no statistical difference were observed regarding assessment of total MV score and each of its components between 2D-Wilkins and 3D-Anwar scores in cases with optimal post-procedural results, but significantly higher total 3D-Anwar score in those with suboptimal results $(p=0.008$ and $p=0.03$ for suboptimal MVA and significant MR respectively), and that was also valid for each of its components (Table 2, Fig. 2). In the fourteen cases with suboptimal BMV outcome, eight cases had moderate total score and six cases had mild total score by $2 \mathrm{D}$-Wilkins score, while 12 cases had severe total score and only two cases had moderate total score (with high scores for calcification and subvalvular affection) by 3D-Anwar score $(p<0.0001)$. Although the 3D-Anwar score showed weak negative correlation with the achieved post-procedural MVA $(r=-$ $0.48, p=0.001)$, the 2D-Wilkins score failed to show any correlation $(r=-0.14, p=0.33)$ (Fig. 3). Moreover, receiver of characteristic (ROC) curve analysis revealed that the 3D-Anwar score was better than 2D-Wilkins score in predicting the occurrence of suboptimal results after BMV (area under curve $($ AUC) $=0.913$, sensitivity $=76.9 \%$, specificity $=94.6 \%$, positive predictive value $(\mathrm{PPV})=83.3 \%$, negative predictive value (NPV) $=92.1 \%$, and $p<0.0001$ vs. AUC $=0.720$, sensitivity $=53.9 \%$, specificity $=$ $81.1 \%, \mathrm{PPV}=50 \%, \mathrm{NPV}=83.3 \%$, and $p=0.01$ respectively) (Fig. 4). Interestingly, the calculated mean post-procedural MVA for all cases $(n=50)$ vs. those with optimal achieved MVA only (i.e., with exclusion of cases of suboptimal achieved MVA) $(n=44)$ were $1.70 \pm 0.29 \mathrm{~cm}^{2}$ vs. $2.2 \pm 0.15 \mathrm{~cm}^{2}$ (as estimated by $2 \mathrm{DE}$ ) and $1.85 \pm 0.36 \mathrm{~cm}^{2}$ vs. $2.18 \pm 0.21 \mathrm{~cm}^{2}$ (as estimated by 3DE).

There was a significant improvement in anterior and posterior commissural splitting after BMV $(p=0.001)$, with better post-procedural posterior commissural splitting as assessed by $3 \mathrm{DE}$ than by $2 \mathrm{DE}(p=0.004)$ (Table 3).

Regarding type of balloon used, 34 cases $(68 \%)$ had BMV using multi-track balloon, while 16 cases $(32 \%)$ by Inoue balloon. In multi-track balloon group, 21, seven, and six cases had balloon size equal, -1 , and +2 the estimated reference balloon sizing respectively, while in Inoue balloon group, 12, two, and two cases had balloon size equal, -1 , and +2 the estimated reference balloon sizing respectively. Multi-track balloon showed better post-procedural posterior commissural splitting than Inoue balloon as estimated by $3 \mathrm{DE}(14.7 \%, 67.6 \%, 17.6 \%$ vs. $43.8 \%, 50 \% .6 .3 \%$ for no, partial, and complete splitting by multi-track vs. Inoue balloon respectively, $p=0.04)$, and no statistical difference was observed between both balloon techniques regarding achieved 
Table 1 Change in MV gradients, PSPAP, and MV area before and after BMV

\begin{tabular}{|c|c|c|c|c|c|c|}
\hline & & Pre-procedural & & Post-procedural & & $P$ \\
\hline \multicolumn{2}{|c|}{ MV Mean gradient } & $19.8 \pm 5.7$ & & $7.5 \pm 3.8$ & & $<0.0001$ \\
\hline \multicolumn{2}{|c|}{ MV Max gradient } & $31.1 \pm 8.5$ & & $16.1 \pm 6.4$ & & $<0.0001$ \\
\hline \multicolumn{2}{|l|}{ PSPAP } & $57.6 \pm 11.5$ & & $39.0 \pm 8.3$ & & $<0.0001$ \\
\hline \multirow[t]{3}{*}{ MV area } & 2D PHT & $0.96 \pm 0.16$ & $p=0.244$ & - & $p=0.008$ & $<0.0001$ \\
\hline & 2D planimetry & $0.92 \pm 0.15$ & & $1.70 \pm 0.29$ & & $<0.0001$ \\
\hline & 3D planimetry & $0.97 \pm 0.16$ & & $1.85 \pm 0.36$ & & $<0.0001$ \\
\hline
\end{tabular}

MV mitral valve, PSPAP peak systolic pulmonary artery pressure, $P H T$ pressure half-time, 2D 2-dimensional, 3D 3-dimensional, BMV balloon mitral valvuloplasty

post-procedural MVA $(p=0.12)$ or MR grade $(p=0.24)$. Interestingly, all cases with suboptimal MVA $(n=6)$ were done using +2 the estimated reference balloon sizing, while all those with significant MR were done using equal, -1 , and -2 the estimated reference balloon sizing $(n=2$, 3,3 respectively).

\section{Discussion}

The ideal MV echocardiographic scoring system must consider the following:

- Qualitative and quantitative global and segmental evaluation of each component of the MV apparatus separately.

- Inclusion of all points that proved to predict and affect the outcome of BMV.

- Ease of application and interpretation within a reasonable time, with high reproducibility and reliability.

- Validity for both transthoracic and transesophageal approaches [16].
The currently used 2D-Wilkins score had basically depended on assessment of four parameters (MV leaflets' mobility, thickness and calcification, and subvalvular involvement), and although its limitations that have been noted for a long time therefore many modifications were developed [17-19]; Wilkins scores $\leq 8 / 16$ persisted as an independent predictor of acute success after BMV in a recent study conducted by Meneguz-Moreno et al. on a very long-term follow-up after percutaneous BMV [20]. The 3DE enables a comprehensive anatomic characterization of leaflet, commissural, and chordal involvement from any unconventional plane [15]. A novel 3D scoring system for MV was introduced by Anwar et al., which basically depended on scoring of both MV leaflets and chordal affection [6].

In the current study, we compared 3D-Anwar and 2D-Wilkins MV scores in assessment of the MV before percutaneous BMV and investigated the additive value of real-time $3 \mathrm{DE}$ in the prediction of immediate adverse outcome of percutaneous BMV. No significant difference was observed in the measured pre-procedural MVA between 2D-planimetry,

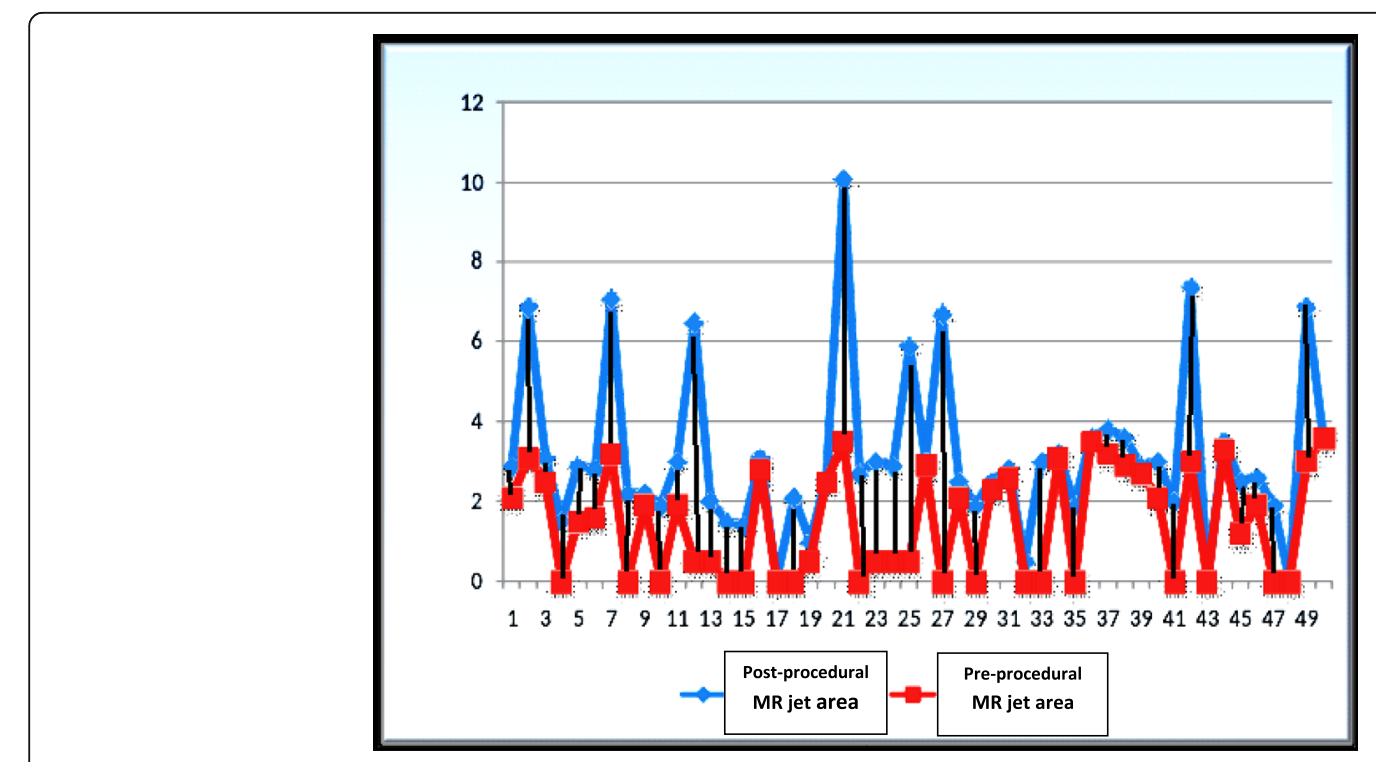

Fig. 1 Change in mitral regurgitation jet area before and after percutaneous balloon mitral valvuloplasty in each case 
Table 2 Comparison between 2D-Wilkins score and 3D=Anwar score in cases with post-procedural optimal results, suboptimal MV area, and significant MR

\begin{tabular}{|c|c|c|c|c|}
\hline & & $2 \mathrm{D}$ & $3 \mathrm{D}$ & $P$ \\
\hline \multirow[t]{5}{*}{ Optimal post-procedural results $(n=36)$} & Mobility & $2.02 \pm 0.51$ & $2.29 \pm 1.11$ & 0.9 \\
\hline & Thickness & $1.88 \pm 0.48$ & $2.09 \pm 0.74$ & 0.5 \\
\hline & Subvalvular apparatus & $1.82 \pm 0.62$ & $2.11 \pm 1.12$ & 0.7 \\
\hline & Calcification & $0.79 \pm 0.52$ & $1.09 \pm 1.37$ & 0.1 \\
\hline & Total score & $6.51 \pm 0.87$ & $7.58 \pm 2.18$ & 0.6 \\
\hline \multirow[t]{5}{*}{ Suboptimal post-procedural MVA $(n=6)$} & Mobility & $1.83 \pm 0.41$ & $4.16 \pm 0.91$ & 0.02 \\
\hline & Thickness & $2.16 \pm 0.41$ & $4.66 \pm 1.03$ & 0.03 \\
\hline & Subvalvular apparatus & $2.17 \pm 0.41$ & $7.01 \pm 0.89$ & 0.01 \\
\hline & Calcification & $0.83 \pm 0.75$ & $3.33 \pm 1.03$ & 0.007 \\
\hline & Total score & $6.99 \pm 1.01$ & $19.16 \pm 3.86$ & 0.008 \\
\hline \multirow[t]{5}{*}{ Significant post-procedural MR $(n=8)$} & Mobility & $1.75 \pm 0.71$ & $3.37 \pm 0.91$ & 0.014 \\
\hline & Thickness & $1.88 \pm 0.64$ & $3.50 \pm 0.53$ & 0.001 \\
\hline & Subvalvular apparatus & $1.75 \pm 0.46$ & $4.12 \pm 0.64$ & 0.01 \\
\hline & Calcification & $1.25 \pm 0.71$ & $5.01 \pm 0.75$ & 0.01 \\
\hline & Total score & $7.79 \pm 1.12$ & $16.0 \pm 2.83$ & 0.03 \\
\hline
\end{tabular}

2D 2-dimensional, 3D 3-dimensional, $M V$ mitral valve, $M R$ mitral regurgitation

$P$ value for comparison between both scores was estimated by $Z$ score

PHT, and 3D-planimetry. Although such results were concordant to those of Messika-Zeitoun et al. [21, 22], but Chu et al. demonstrated that PHT had overestimated the MVA compared to continuity equation (CEQ) $(p=0.037)$, whereas no significant difference was observed between 3DE and CEQ $(p=0.61)$ [23]. Moreover, Schlosshan et al. showed that MVA by 3D-TEE measurements were significantly lower compared to it by 2D-TTE $(p=0.005)$ and PHT $(p<0.0001)$, but marginally greater than MVA by CEQ $(p=0.82)$ [24]. Also Min et al. had considered 3DTEE for accurate MVA assessment because of overestimation of MVA by 2D-planimetry [25].
We observed a significant difference between 2DE and 3DE regarding MV score (for total score and each of its component) in cases with suboptimal post-procedural MVA or significant MR, while this was not observed in cases with optimal post-procedural results. Whereas 57\% and $43 \%$ of them had moderate and mild total 2D-Wilkins score respectively, while $86 \%$ had severe total 3DAnwar score and only 14\% had moderate score. This could be explained by the underestimation of MV score especially the degree of calcification and subvalvular apparatus affection by 2DE, while 3DE allowed for better visualization of $\mathrm{MV}$ and subvalvular apparatus from the

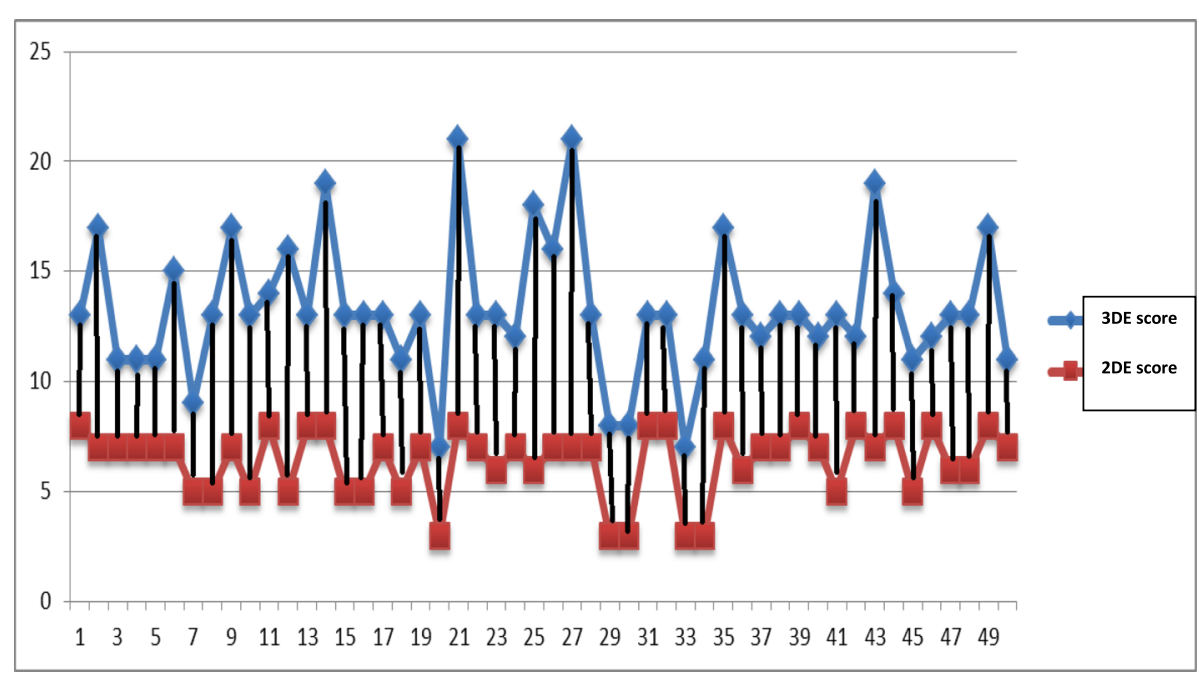

Fig. 2 Pre-procedural 2D-Wilkins score and 3D-Anwar score in each case 


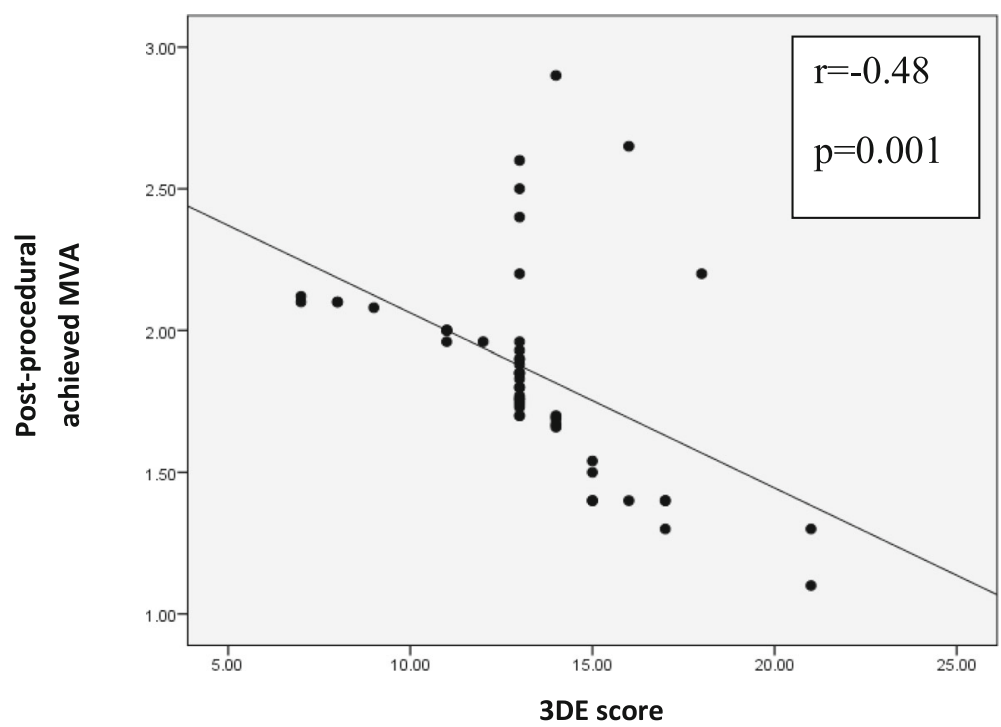

Fig. 3 Correlation between 3D-Anwar score and achieved post-procedural mitral valve area

ventricular perspective, which gave a respective quantification of leaflet motion and calcification, chordate shortening and fusion, commissural union, and papillary muscle fibrosis [6]. A significant negative correlation was obtained between 3D score and the achieved postprocedural MVA, which was not obtained with 2D score. These results were comparable with those of Anwar et al. who demonstrated the superiority of $3 \mathrm{DE}$ over $2 \mathrm{DE}$ in estimation of MV score, as $10 \%$ of cases had high 2DWilkins score while this percent increased up to $16 \%$ by 3D-Anwar score. Moreover; they found that 3DE score components for leaflet mobility and subvalvular thickening were independent predictors of procedural success ( $p=0.004$ and 0.04 respectively). They also observed that the high mean trans-mitral gradient in $16.6 \%$ of patients with procedural success was in those with moderate or severe subvalvular score by 3DE despite being mild by 2D-wilkins score. Meanwhile, calcification was the only independent predictor for development of significant MR, with four out of 17 of those patients had severe 3DE score while having it mild by 2D-Wilkins score [6]. Nevertheless, discordant results were demonstrated by Aslanabadi et al. that 2D calcification score was useful enough for identifying patients likely to have MR development or increase after BMV [26]. Moreover, Rifaie et al. had also demonstrated that using 2DE scores that basically depended on calcification (especially commissural) and subvalvular involvement could correlate well with poor outcome in BMV patients [27].

In the current study, ROC curve analysis revealed better prediction for occurrence of suboptimal results by 3D-Anwar score $(>14)$ than 2D-Wilkins score $(>8)$.

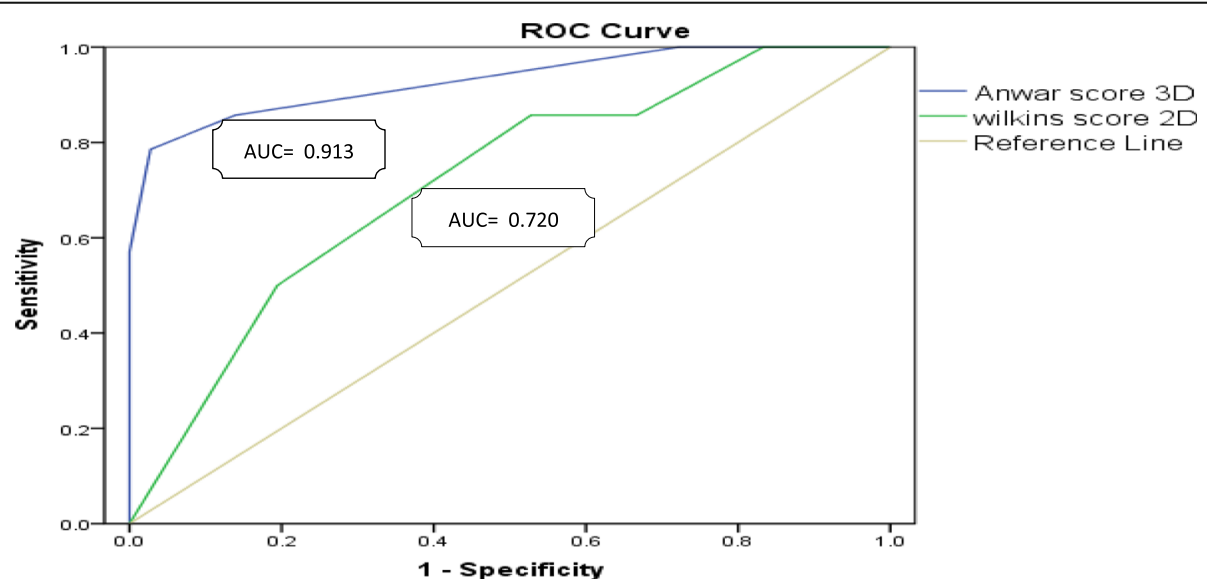

Fig. 4 Roc curve analysis for 3D-Anwar score and 2D-Wilkins score in predicting the occurrence of suboptimal results after percutaneous balloon mitral valvuloplasty 
Table 3 Pre-procedural commissural affection and post-procedural commissural splitting as estimated by 2D and 3D echocardiography

\begin{tabular}{|c|c|c|c|c|c|c|c|}
\hline & & \multicolumn{3}{|c|}{$\begin{array}{l}\text { Pre-procedural } \\
\text { Commissural affection }\end{array}$} & \multicolumn{3}{|c|}{$\begin{array}{l}\text { Post-procedural } \\
\text { Commissural splitting }\end{array}$} \\
\hline & & $2 \mathrm{D}$ & $3 D$ & $p$ & $2 \mathrm{D}$ & $3 D$ & $p$ \\
\hline \multirow[t]{3}{*}{ Anterior commissure } & No & $46(92 \%)$ & $47(94 \%)$ & 0.93 & $8(16 \%)$ & $4(8 \%)$ & 0.18 \\
\hline & Partial & $4(8 \%)$ & $3(6 \%)$ & 0.6 & $28(56 \%)$ & $24(48 \%)$ & 0.4 \\
\hline & Complete & 0 & 0 & - & $14(28 \%)$ & $22(44 \%)$ & 0.9 \\
\hline \multirow[t]{3}{*}{ Posterior commissure } & No & $47(94 \%)$ & $46(92 \%)$ & 0.93 & $12(24 \%)$ & $5(10 \%)$ & 0.07 \\
\hline & Partial & $3(6 \%)$ & $4(8 \%)$ & 0.6 & $31(62 \%)$ & 25 (50\%) & 0.8 \\
\hline & Complete & 0 & 0 & - & 7 (14.0\%) & $20(40 \%)$ & 0.004 \\
\hline
\end{tabular}

Moreover, better post-procedural MVA was obtained when excluding the six cases with suboptimal achieved MVA, those who might be excluded according to their high 3D-Anwar score.

The assessment of leaflet calcification and its distribution along leaflets' parts play an important role in determining the outcome of BMV, as the percentage of success decreases and the incidence of complication increases with increased extent of calcification. 3DE could predict the extent and distribution of calcification in each scallop from single short axis cut plain; meanwhile, multiple cut planes are needed for detecting calcification in all scallops of both MV leaflets by 2DWilkins score [28]. Calcification of commissures is one of the strong predictors of outcome after BMV because it affects the degree of commissural splitting. That is why in the new 3DE score, calcification at the commissural parts of leaflet was described by a higher score than the middle leaflets calcification [29].

We observed a significant improvement in anterior and posterior commissural splitting after BMV by both 2DE and by 3DE. Although no significant difference regarding pre-procedural commissural affection was observed between 2DE and 3DE, but favorable results were obtained regarding post-procedural posterior commissural splitting when evaluated by 3DE. Several studies showed the splitting of one or both commissures along the natural planes as the mechanism of dilatation in BMV $[6,30]$. Concordant with our results were those of Messika-Zeitoun et al., as 2DE underestimated the degree of commissural opening after BMV in 33\% of patients compared to $3 \mathrm{DE}$ and agreement between methods was weak $(\kappa=0.41)$, explaining that by easy visualization of the degree of commissural opening by 3DE [22]. Meanwhile, Anwar et al. showed comparable results regarding achieved post-procedural commissural splitting by 2DE and 3DE [6].

In the current study, favorable post-procedural posterior commissural splitting was obtained by multi-track balloon than Inoue balloon, and no significant difference regarding post-procedural achieved MVA or MR grade between both techniques. These results were concordant to those of El-sayed et al. who compared the immediate results of percutaneous mitral commissurotomy using metallic valvotome, Inoue balloon, and double-balloon techniques. Similar higher depth score for only posterior commissural splitting was observed in double-balloon group compared to Inoue balloon group $(p=0.006)$, with comparable resulting MR grades, but unlike our results they showed better achieved MVA with double-balloon technique $(p=0.01)$ [9]. This could be explained by the ability of the double-balloon to fit and simultaneously press on both commissures, while Inoue balloon exerted its pressure mainly on the anterior one [31]. Meanwhile, Oraby and Youssef showed a better bilateral commissurotomy with multi-track balloon, with higher incidence of mild MR $(p=0.003)$, while no significant differences regarding moderate to severe MR after BMV [32].

Our surprising observation that suboptimal achieved MVA was obtained with larger balloon sizes and significant MR with smaller balloon sizes may support the claim that only mitral apparatus anatomy and score that could determine the occurrence of post-procedural adverse outcome, regardless type or size of the balloon used.

\section{Conclusion}

From the previous data, we concluded that 3DE was an accurate tool for assessing MV before percutaneous BMV, which had a valuable role in assessing MV score especially calcification and subvalvular apparatus, and correlated well with the immediate post-procedural outcome. The 3D-Anwar score appeared as a better tool that may gave detailed morphological assessment of MV, which would help in the proper selection of the therapeutic strategy for MS and predict procedural success or immediate adverse outcome than the traditional 2D-Wilkins score.

At the start of learning, complementary use of both the 2D- and 3D-scores on large-scale before BMV will facilitate future standardization of 3DE for both quantitative and qualitative assessment of the MV. 


\section{Limitations}

The study population was initially selected for BMV depending on 2D-Wilkins score only (according to the current guidelines recommendations). Perhaps it would be better to test concomitant use of 3DE and 3D-Anwar score for the initial patient selection, which might be reflected on better procedural outcome and lesser incidence of suboptimal results than those obtained.

\section{Additional file}

Additional file 1: Anwar et al. real-time three-dimensional echocardiographic scoring system [6].

\section{Abbreviations}

2D: Two-dimensional; 2DE: Two-dimensional echocardiography; 2DTEE: Three-dimensional transesophageal echocardiography; 2D-TTE: Twodimensional transthoracic echocardiography; 3D: Three-dimensional; 3DE: Three-dimensional echocardiography; AUC: Area under curve; BMV: Balloon mitral valvuloplasty; CEQ: Continuity equation; ECG: Electrocardiogram; LA: Left atrium; MR: Mitral regurgitation; MS: Mitral stenosis; MVA: Mitral valve area; PHT: Pressure half time; PSPAP: Peak systolic pulmonary artery pressure; ROC: Receiver of characteristic; SD: Standard deviation; SPSS: Statistical package for the social sciences;

TEE: Transesophageal echocardiography; TTE: Transthoracic echocardiography

\section{Acknowledgments}

Not applicable.

\section{Ethical approval and consent to participate}

The study protocol was approved by the local Ethical Committee of Minia University Faculty of Medicine (reference number is not applicable) and was in agreement with the "World Medical Association Declaration of Helsinki." An informed written consent for accepting the participation in the study was obtained from every participating patient.

\section{Authors' contributions}

HF has made substantial contributions to the conception and design of the work, acquisition of data, drafted and substantively revised the manuscript. AS has made substantial contributions in operating BMV and echocardiography data acquisition and also drafted the manuscript. MM has made substantial contributions to echocardiography data acquisition. MS has made substantial contributions to echocardiography data acquisition. KM has made substantial contributions to the conception and design of the work, and also substantively revised the manuscript. HM has made substantial contributions to the conception and design of the work, operating BMV, acquisition of data, and also substantively revised the manuscript. Al has made substantial contributions to the conception and design of the work, and also revised the manuscript. All authors have read and approved the manuscript.

\section{Funding}

No funding sources.

\section{Availability of data and materials}

The datasets generated and/or analyzed during the current study are not publicly available as included in ongoing researches, but are available from corresponding author on reasonable request.

\section{Consent for publication}

Not applicable.

\section{Competing interests}

The authors declare that they have no competing interests.

\section{Author details}

${ }^{1}$ Cardiology Department, Faculty of Medicine, Minia University, Minya 61111 , Egypt. ${ }^{2}$ Cardiology Department, Faculty of Medicine, Beni-Suef University, Beni Suef, Egypt. ${ }^{3}$ Cardiology Department, Faculty of Medicine, El-Azhar University, Cairo, Egypt.

Received: 25 June 2019 Accepted: 23 August 2019

Published online: 18 September 2019

\section{References}

1. Inoue K, Owaki T, Nakamura T, Kitamura F, Miyamoto N (1984) Clinical application of transvenous mitral commissurotomy by a new balloon catheter. J Thorac Cardiovasc Surg 87(3):394-402

2. Turi ZG, Reyes VP, Raju BS, Raju AR, Kumar DN, Rajagopal P et al (1991) Percutaneous balloon versus surgical closed commissurotomy for mitral stenosis. A prospective randomized trial. Circulation 83(4):1179-1185

3. Soliman OI, Anwar AM, Metawei AK, McGhie JS, Geleijnse ML, Ten Cate FJ (2011) New scores for the assessment of mitral stenosis using real-time three-dimensional echocardiography. Curr Cardiovasc Imaging Rep 4(5):370-377

4. Raafat SS, Ramzy AA, El-Hadidy AF, Abd Allah MA, Hanna HF (2018) Mitral leaflet separation index. An easy two dimensional echocardiography technique for assessment of mitral valve area before and after percutaneous balloon mitral valvuloplasty. Egypt Heart J 70(3):195-201

5. Goldstein SA, Lindsay J (2010) Do we need more echo scores for balloon mitral valvuloplasty? J Am Soc Echocardiogr 23(1):23-25

6. Anwar AM, Attia WM, Nosir YF, Soliman OI, Mosad MA, Othman M et al (2010) Validation of a new score for the assessment of mitral stenosis using real-time three-dimensional echocardiography. J Am Soc Echocardiogr 23(1):13-22

7. Baumgartner H, Falk V, Bax JJ, De Bonis M, Hamm C, Holm PJ et al 2017 ESC/EACTS Guidelines for the management of valvular heart disease. Eur Heart J 38, 36:2739-2791

8. Wilkinss GT, Weyman AE, Abascal VM, Block PC, Palacios IF (1988) Percutaneous balloon dilatation of the mitral valve: an analysis of echocardiographic variables related to outcome and the mechanism of dilatation. Heart 60(4):299-308

9. El-Sayed MA, Anwar AM (2000) Comparative study between various method of percutaneous transvenous mitral commissurotomy Metallic valvotome, Inoue balloon, and double balloon techniques (VID) study. J Interv Cardiol 13(5):357-364

10. Roberts BJ, Grayburn PA (2003) Color flow imaging of the vena contracta in mitral regurgitation: technical considerations. J Am Soc Echocardiogr 16(9):1002-1006

11. Baumgartner H, Hung J, Bermejo J, Chambers JB, Evangelista A, Griffin BP et al (2009) Echocardiographic assessment of valve stenosis: EAE/ASE recommendations for clinical practice. J Am Soc Echocardiogr 22(1):1-23

12. Solis J, Piro V, Loughlin G, de Prada JA (2013) How to grade mitral regurgitation; an integrative approach. Cardiol Clin 31(2):169-175

13. Feigenbaum $H$, Armstrong W, Ryan T (2005) Hemodynamics. Feigenbaum's echocardiography $6^{\text {th }}$ Ed. Lippincott Williams \& Wilkinss, Philadelphia, pp 234-235

14. Lang RM, Badano LP, Tsang W, Adams DH, Agricola E, Buck T et al (2012) EAE/ASE recommendations for image acquisition and display using three-dimensional echocardiography. Eur Heart J Cardiovasc Imaging 13(1):1-46

15. Muraru D, Cattarina M, Boccalini F, Dal Lin C, Peluso D, Zoppellaro G et al (2013) Mitral valve anatomy and function: new insights from threedimensional echocardiography. J Cardiovasc Med 14(2):91-99

16. Prendergast B, Shaw T, lung B, Vahanian A, Northridge D (2003) Contemporary criteria for the selection of patients for percutaneous balloon mitral valvuloplasty. Heart 87(5):401-404

17. Padial L, Freitas N, Sagie A, Newell J, Weyman A, Levine R et al (1996) Echocardiography can predict which patients will develop severe mitral regurgitation after percutaneous mitral valvulotomy. JACC 27(5):1225-1231

18. Padial L, Abascal V, Moreno P, Weyman A, Levine R, Palacios I (1999) Echocardiography can predict the development of severe mitral regurgitation after percutaneous mitral valvuloplasty by the Inoue technique. Am J Cardiol 83(8):1210-1213 
19. Nunes MC, Tan TC, Elmariah S, do Lago R, Margey R, Cruz-Gonzalez I et al (2014) The echo score revisited: Impact of incorporating commissural morphology and leaflet displacement to the prediction of outcome for patients undergoing percuta. eous mitral valvuloplasty. Circulation 129(8):886-895

20. Meneguz-Moreno RA, JR-Jr C, Gomes NL, SLN B, Ramos A, Meneghelo Z et al $(2018,1945)$ Very long term follow-up after percutaneous balloon mitral valvuloplasty. JACC Cardiovasc Interv 11(19):-52

21. Messika-Zeitoun D, Meizels A, Cachier A, Scheuble A, Fondard O, Brochet E et al (2005) Echocardiographic evaluation of the mitral valve area before and after percutaneous mitral commissurotomy. The pressure half-time method revisited. J Am Soc Echocardiogr 18(12):1409-1414

22. Messika-Zeitoun D, Brochet E, Holmin C, Rosenbaum D, Cormier B, Serfaty JM et al (2007) Three-dimensional evaluation of the mitral valve area and commissural opening before and after percutaneous mitral commissurotomy in patients with mitral stenosis. Eur heart J 28(1):72-79

23. Chu JW, Levine R, Chua S, Poh KK, Morris E, Hua L (2008) Assessing mitral valve area and orifice geometry in calcific mitral stenosis: a new solution by real-time three-dimensional echocardiography. J Am Soc Echocardiogr 21(9):1006-1009

24. Schlosshan D, Aggarwal G, Mathur G, Allan R, Cranney G (2011) Real-time $3 \mathrm{D}$ transesophageal echocardiography for the evaluation of rheumatic mitral stenosis. JACC Cardiovasc Imag 4(6):580-588

25. Min SY, Song JM, Kim YJ, Park HK, Seo MO, Lee MS et al (2013) Discrepancy between mitral valve areas measured by two-dimensional planimetry and three-dimensional transoesophageal echocardiography in patients with mitral stenosis. Heart 99(4):219-221

26. Aslanabadi N, Toufan M, Salehi R, Alizadehasl A, Ghaffari S, Sohrabi B et al (2014) Mitral regurgitation after percutaneous balloon mitral valvotomy in patients with rheumatic mitral stenosis: a single-center study. J Tehran Heart Cent 9(3):109-114

27. Rifaie O, Esmat I, Abdel-Rahman M, Nammas W (2009) Can a novel echocardiographic score better predict outcome after percutaneous balloon mitral valvuloplasty? Echocardiogr J Card 26(2):119-127

28. Lange A, Palka P, Burstow DJ, Godman MJ (2001) Three-dimensional echocardiography: historical development and current applications. J Am Soc Echocardiogr 14(5):403-412

29. Sutaria N, Northridge D, Shaw T (2000) Significance of commissural calcification on outcome of mitral balloon valvotomy. Heart 84(4):398-402

30. Messika-Zeitoun D, Blanc J, lung B, Brochet E, Cormier B, Himbert D et al (2009) Impact of degree of commissural opening after percutaneous mitral commissurotomy on long-term outcome. JACC Cardiovasc Imag 2(1):1-7

31. Levine R, Handschumacher M, Sanfilippo A, Hagege A, Harrigan P, Marshall J et al (1989) Three-dimensional echocardiographic reconstruction of the mitral valve, with implications for the diagnosis of mitral valve prolapse. Circulation 80(3):589-598

32. Oraby M, Youssef A (2011) Immediate and 18-month outcome of balloon mitral valvuloplasty: comparison of Inoue and Multi-track System. J Interv Cardiol 25(1):47-52

\section{Publisher's Note}

Springer Nature remains neutral with regard to jurisdictional claims in published maps and institutional affiliations.

\section{Submit your manuscript to a SpringerOpen ${ }^{\circ}$ journal and benefit from:}

- Convenient online submission

- Rigorous peer review

- Open access: articles freely available online

- High visibility within the field

- Retaining the copyright to your article

Submit your next manuscript at $\boldsymbol{\nabla}$ springeropen.com 